\title{
Effect of weaning age on growth, mammary gland development, and immune function in Holstein Friesian calves fed conserved alfalfa (FiberStart)
}

\author{
S. McCoard, ${ }^{1}$ A. Heiser, ${ }^{1}$ K. Lowe, ${ }^{1}$ A. Molenaar, ${ }^{1}$ P. MacLean, ${ }^{2}$ P. Johnstone, ${ }^{1,3}$ S. Leath, ${ }^{2}$ S. O. Hoskin, ${ }^{4}$ \\ and M. A. Khan ${ }^{1 *}$ \\ ${ }^{1}$ AgResearch Ltd., Grasslands Research Centre, Private Bag 11008, Palmerston North 4474, New Zealand \\ ${ }^{2}$ AgResearch Ltd., Lincoln Research Centre, Private Bag 4749, Christchurch 8140, New Zealand \\ ${ }^{3}$ AgResearch Ltd., Ruakura Research Centre, Private Bag 3123, Hamilton 3240, New Zealand \\ ${ }^{4}$ Fiber Fresh Feeds Ltd, RD2, Reporoa, New Zealand
}

\section{ABSTRACT}

This study aimed to evaluate intake, body growth, and the development of the rumen, mammary gland, and immune system in Holstein Friesian calves reared for $100 \mathrm{~d}$ on the commercially available feed FiberStart (conserved alfalfa, Medicago sativa; Fiber Fresh Feeds Ltd., Reporoa, New Zealand) and fed calf milk replacer (CMR) for either 56 or $91 \mathrm{~d}$. Eighty calves (40 bulls and 40 heifer calves) were reared indoors in groups (n $=5$ of the same sex/pen). All calves were fed $4 \mathrm{~L}$ of $\mathrm{CMR} / \mathrm{d}(175 \mathrm{~g} / \mathrm{L}$ of CMR) in 2 feeds/d for the first 10 $\mathrm{d}$ and then 1 feed/d until d 49 or 84 . The calves were gradually weaned by d 56 (earlier weaned; $\mathrm{n}=8$ pens) and d 91 (later weaned; $\mathrm{n}=8$ pens). All calves were fed FiberStart ad libitum as the only solid feed source from d 1 to 100 of the study. Irrespective of treatment, all calves had similar body weights at d $0(40.9 \pm 3.0$ $\mathrm{kg})$ and $\mathrm{d} 49(74.2 \pm 5.1 \mathrm{~kg})$ of the study. Calf sex had no effect on intake, growth, blood, and immune system parameters. Earlier-weaned calves consumed $18 \%$ more solid feed dry matter but had 16\% lower body weight gain (28.9 vs. $38.5 \mathrm{~kg}$, respectively) from d 56 to 100 relative to later-weaned calves, resulting in different body weight at $100 \mathrm{~d}$ (104 vs. $121 \pm 1.3 \mathrm{~kg}$ ). Although earlier-weaned calves could compensate for the loss of CMR dry matter and crude protein intake from d 56 to 100 by increasing forage intake, they were unable to compensate for the loss of energy from the CMR by increasing solid feed consumption. Plasma $\beta$-hydroxybutyrate concentrations were $52 \%$ greater in earlier-weaned calves than in later-weaned calves at $\mathrm{d}$ 84, indicating greater metabolic activity of the rumen wall. The duration of CMR feeding had no influence on humoral or cell-mediated immune functions of the calves, as evidenced by a lack of effect on antivaccine

Received August 29, 2018.

Accepted March 18, 2019.

*Corresponding author: ajmal.khan@agresearch.co.nz antibody responses as well as on immune gene expression. Earlier- versus later-weaned heifer calves had 5\% lower mammary gland mass, indicating that greater energy supply increased mammary mass. The results of this experiment demonstrate the ability to artificially rear dairy calves on a conserved alfalfa as the only solid feed. Furthermore, earlier weaning off CMR promotes solid feed intake and an associated increase in blood $\beta$-hydroxybutyrate, an indicator of rumen development, but increasing the duration of CMR feeding improves growth and mammary gland mass by $\mathrm{d} 100$. The implications of these findings on lifetime growth, health, and milk production in dairy heifers warrant further investigation.

Key words: forage, rumen development, solid feed, weaning, heifer calf

\section{INTRODUCTION}

Initiation of solid feed intake primarily drives physical and metabolic development of the rumen, which is necessary for a calf to shift reliance on nutrients from milk to solid feeds (Baldwin et al., 2004). Solid feeds containing readily fermentable carbohydrates, including forage (Yu et al., 2003), and grain-based starter feeds stimulate rumen papillae development, including changes in the epithelium of the forestomach (Baldwin et al., 2004). However, dietary forage also plays a key role in the physical development of the rumen and stabilizes rumen fermentation and $\mathrm{pH}$ (Laarman and Oba, 2011; Khan et al., 2016) in artificially reared young calves.

The amount and duration of milk feeding is an important factor influencing growth and development in artificially reared calves. However, most artificial calfrearing systems are economically driven to minimize milk costs by restricting milk allowance and weaning earlier. It has been demonstrated that calves receiving greater (e.g., 8 vs. 4 L/d) amounts of milk (Khan et al., 2011) or weaned later had improved growth perfor- 
mance around weaning (Sweeney et al., 2010; Eckert et al., 2015). However, solid feed intake is negatively correlated with the amount of milk supplied to calves (Khan et al., 2011). Therefore, weaning age, weaning method, and type of starter feed offered to calves are important factors for maintaining the nutrient supply needed for the development and growth of calves around weaning and early postweaning (Khan et al., 2016).

Most published calf milk feeding and weaning studies have used grain-based starter feeds (Khan et al., 2011; Eckert et al., 2015; de Passillé and Rushen, 2016). The effect of the duration of milk or calf milk replacer (CMR) feeding on the performance of calves reared on a forage-only diet has not been fully explored. Generally, forage is considered less digestible and energy dense than grains for young calves; hence, access to forage preweaning is often discouraged in artificial calf-rearing systems (Khan et al., 2016). However, it is important to note that calves raised by their dams in extensive grazing systems (e.g., cow-calf operations; Cafe et al., 2006) and young ruminants reared in some pastoral systems would not typically have access to grain-based feeds (Khan et al., 2016). The effect of forage as the only source of solid feed in artificial calf-rearing systems is not well established, yet a growing number of niche livestock product markets now demand more natural, grain-free rearing of animals (Xue et al., 2010).

Interactions between nutrition and immunity in general are well established. The level of feed allowance, composition of both the milk and solid feed, and feeding management could influence both development and expression of immune responses in developing calves (Ballou, 2012). However, studies in which immune responses were measured in calves reared on different milk allowances and weaned at various ages have shown inconclusive results (Foote et al., 2007; Ballou, 2012). Therefore, further research is needed to understand how early-life nutrition and feeding practices can influence immune function (e.g., vaccine response) in calves.

Mammary gland development is sensitive to the changes in preweaning nutrient supply, with increased total nutrient intake associated with enhanced mammary gland development (Meyer et al., 2006). It has also been postulated that the quality and quantity (e.g., both energy and protein) of feed offered to calves preweaning may influence their mammary gland development (Geiger et al., 2016; Soberon, and Van Amburgh, 2017) and future milk production (Chester-Jones et al., 2017). Weaning age can affect the nutrient supply and growth of developing heifer calves (Eckert et al., 2015; de Passillé and Rushen, 2016), which might also influence mammary gland development.

The aim of this study was to evaluate the growth performance and development of the rumen, mammary gland, and immune system in Holstein Friesian calves fed CMR for 56 or $91 \mathrm{~d}$ along with the commercially available feed FiberStart [modified biofermentation alfalfa (Medicago sativa) high-nutritional fiber treated with Xanotyde; Fiber Fresh Feeds Ltd., Reporoa, New Zealand] as the only source of solid feed for a 100-d rearing period. We hypothesized that extended CMR feeding would provide additional nutrients (protein and energy), thereby enhancing growth and immune function in both male and female calves and mammary gland mass in female calves receiving a forage (FiberStart) as the only source of solid feed.

\section{MATERIALS AND METHODS}

\section{Trial Location and Animal Care}

The animal experiment was conducted in Reporoa, New Zealand, with calves reared in autumn 2015. All animal manipulations in this study, including sampling, welfare, and husbandry, were conducted in compliance with the institutional Code of Ethical Conduct for the Use of Animals in Research, Testing, and Teaching, as prescribed in the Animal Welfare Act of 1999 and its amendments (New Zealand). Manipulations were approved by the AgResearch Grasslands Animal Ethics Committee (approval number 13516).

\section{Animals, Feeds, and Management}

Eighty Holstein Friesian bull and heifer calves ( $\mathrm{n}=$ 40 of each sex; $40.9 \pm 3.0 \mathrm{~kg}$ ) were sourced from a single farm at $8 \pm 1 \mathrm{~d}$ of age. The day of arrival was considered d 0 of the study. These 80 calves were retained for the trial based on plasma IgG levels as an indicator of colostral transfer, physical examination, BW, rectal temperature, potential abnormalities (e.g., umbilical ill, hernia), ease of feeding, and fecal consistency. The calves were reared in a shed with clean, dry pens containing fresh untreated wood shaving bedding that was replaced weekly. The rearing facility was adequately ventilated at both ends of the shed to facilitate continuous airflow. Clean, fresh water was available ad libitum. As part of the standard animal facility practice, upon arrival the calves were given 3 doses of ImmuStart (Nutritech, Auckland, New Zealand), which contains vitamins A and $\mathrm{E}$ and microencapsulated probiotic bacteria to support the immune system. The calves were debudded at d 21 of the trial using a hot iron under local anesthesia by an experienced contractor and vaccinated against clostridial infection with a 10:1 vaccine (Covexin 10, Schering-Plough Animal Health Ltd., Wellington, New Zealand) at d 49 followed by a booster at d 70. All calves were fed a casein-based CMR containing the 
coccidiostat Deccox (AnCalf, NZAgbiz, Temuka, New Zealand) and a premix to provide minerals, vitamins, and Actigen (a yeast-derived carbohydrate; Alltech Inc., Nicholasville, KY).

The calves $(\mathrm{n}=80)$ were randomly allocated to 1 of 2 treatment groups based weaning off CMR on either d 56 (referred to as the earlier-weaning group) or d 91 (referred to as the later-weaning group). Each treatment had 20 heifers and 20 bulls in 8 pens per treatment group ( 5 calves of the same-sex in a pen). The treatments were balanced for initial BW, age, $\operatorname{IgG}$, and date of collection of calves from the farm. Calves within each pen were fed CMR through teats attached to a group feeder. Calves in the earlier-weaning group were fed CMR twice daily ( $2 \mathrm{~L} /$ feed at $175 \mathrm{~g}$ of CMR/L) for the first $10 \mathrm{~d}$ of the trial and then transitioned to oncedaily feeding by d 12 of the trial (gradually shifting the amount of CMR from evening to morning feeding 60:40, 70:30, and 80:20 over $3 \mathrm{~d}$ ), reaching a final CMR allocation of $4 \mathrm{~L} /$ feed at $175 \mathrm{~g} / \mathrm{L}$ of CMR $(700 \mathrm{~g}$ of $\mathrm{CMR} / \mathrm{d}$ ). Milk replacer feeding continued once daily until d 49, when the CMR was gradually removed by d 56 for earlier-weaned calves. Later-weaned calves were fed as per the earlier-weaned calves until d 84 of the study, with subsequent weaning by d 91 . On both treatments, CMR was reduced by $0.5 \mathrm{~L} /$ calf per day to complete weaning within a week.

The calves were offered ad libitum FiberStart as the only source of solid feed from the start of the study for $100 \mathrm{~d}$ (i.e., until the end of the trial). Xanotyde is a proprietary formulation of Fiber Fresh Feeds that comprises natural ingredients and microbes to support the modified biofermentation process of alfalfa. Ad libitum solid feed was presented fresh daily from troughs using vacuum-sealed blocks with one edge opened to present fresh feed. The exposed surface was refreshed daily to prevent stale forage or any spoilage and to stimulate intake. Particle size of the FiberStart was determined on an as-fed basis from 3 samples from 3 different bags of feed, each from a different batch. On average, the particle size was $<1 \mathrm{~cm}$ (45.1\%), 1 to $2 \mathrm{~cm}(14.5 \%)$, 2 to $3 \mathrm{~cm}(9.8 \%)$, and $3+\mathrm{cm}(30.6 \%), \pm 6 \% \mathrm{SEM}$ between batches. A commercial mineralized salt block (Summit Multi Mineral Salt Block, Dominion Salt Ltd., Mount Maunganui, New Zealand; salt 89\%, Ca $2.79 \%$, Cu 1,250 mg/kg, Zn $580 \mathrm{mg} / \mathrm{kg}$, I $94 \mathrm{mg} / \mathrm{kg}$, Co $65 \mathrm{mg} / \mathrm{kg}$, Se $3 \mathrm{mg} / \mathrm{kg}$, Fe $89 \mathrm{mg} / \mathrm{kg}$, and commercial flavoring agent) was provided for all calves during the $100-d$ trial. All calves were individually monitored for their health daily. No calf death or major health issues were observed during the trial.

Daily CMR intake and weekly solid feed intake in each pen were recorded as the difference between feed offered and feed refused. Samples of the CMR and solid
Table 1. Chemical composition (\% of DM, unless otherwise noted) of calf milk replacer $\left(\mathrm{AnCalf}^{1}\right)$

\begin{tabular}{lc}
\hline Component & AnCalf \\
\hline DM (\% of wet matter) & 96.4 \\
Ash $(\mathrm{g} / 100 \mathrm{~g})$ & 6.2 \\
Total nitrogen & 4.2 \\
CP & 26.6 \\
Total fat & 21.7 \\
Total carbohydrate & 41.8 \\
\hline
\end{tabular}

${ }^{1} \mathrm{~A}$ casein-based milk replacer containing coccidiostat, minerals and vitamins premix, and Actigen (NZAgbiz, Temuka, New Zealand).

feed diets, which were from a single batch, were collected weekly throughout the trial. Composition of the CMR (Table 1) was determined using wet chemistry procedures (RJ Hill Labs, Hamilton, New Zealand). Chemical composition of the weekly feed samples (Table 2) was evaluated in 4 samples pooled over 3- or 4-wk periods using wet chemistry procedures (RJ Hill Labs).

Body length (distance between the points of the shoulder and rump), heart girth (circumference of the chest behind the front legs), and withers height (distance from the base of the front feet to the withers) were recorded as indicators of skeletal growth. Body barrel (maximum circumference of the body over the rumen) was measured as an indicator of gut fill. These parameters were measured at the start of the trial, $\mathrm{d}$ 49 (start of weaning off CMR for the earlier-weaned

Table 2. Chemical composition (\% of DM, unless otherwise noted) of solid feed (FiberStart ${ }^{1}$ )

\begin{tabular}{lc}
\hline Component & FiberStart \\
\hline DM (\% of wet matter) & 43.9 \\
CP & 19.2 \\
NDF & 44.2 \\
ADF & 37.3 \\
Starch & 0.9 \\
IVOMD & 58.1 \\
ME (MJ/kg of DM) & 9.3 \\
Crude fat & 2.1 \\
P (\%) & 0.27 \\
K (\%) & 2.5 \\
S (\%) & 0.37 \\
Ca $(\%)$ & 1.2 \\
Mg (\%) & 0.21 \\
Na (\%) & 0.02 \\
Fe (mg/kg) & 213 \\
Mn (mg/kg) & 38 \\
Zn (mg/kg) & 22 \\
Cu (mg/kg) & 9.3 \\
Bo (mg/kg) & 37 \\
Mo (mg/kg) & 0.39 \\
Co (mg/kg) & 0.24 \\
Se (mg/kg) & 0.03 \\
\hline
\end{tabular}

${ }^{1}$ Modified biofermentation alfalfa high-nutritional fiber (Medicago sativa) treated with Xanotyde (Fiber Fresh Feeds Ltd., Reporoa, New Zealand).

${ }^{2} \mathrm{IVOMD}=$ samples were incubated for $24 \mathrm{~h}$ to determine in vitro OM digestibility. 
calves), and d 100 of the trial by the same operator. All calves remained in their assigned pen for the duration of the study.

\section{Blood Metabolites and Immune Function}

Blood samples (10 mL in serum tubes, Vacutainer, Becton Dickinson, Franklin Lakes, NJ) were collected from the jugular vein of 20 heifer calves and 20 bull calves (10 of each sex/group) on d 49 and 84 (the same animals each time). Serum blood tubes were centrifuged at room temperature for $15 \mathrm{~min}$ at $2,000 \times \mathrm{g}$. Then, serum was harvested and frozen at $-20^{\circ} \mathrm{C}$ until analysis for selected metabolites, including BHB (as a marker of rumen development; Quigley et al., 1991), glucose, total protein, urea $\mathrm{N}$, triglycerides, and nonesterified fatty acid concentrations. All blood metabolite tests were performed using the P800 module of the Roche modular platform (New Zealand Veterinary Pathology, Palmerston North, New Zealand). Anticlostridal antibody responses in sera on $\mathrm{d} 49$ (prevaccination) and 84 (14 d after booster vaccination) were evaluated using an ELISA method (Wedlock et al., 2008). Antibody levels were expressed as optical density readings at a serum dilution of 1:200 or as titer postvaccination (i.e., the serum dilution that showed lower optical density reading than the 1:200 prevaccination reading).

Whole-blood samples were collected by jugular venipuncture into tubes containing lithium heparin as an anticoagulant (Vacutainer, Becton Dickinson) for the gene expression analysis at d 100 of the trial. Tubes were incubated for $22 \mathrm{~h}$ at $37^{\circ} \mathrm{C}$ in $5 \% \mathrm{CO}_{2}$. Prewarmed $\left(37^{\circ} \mathrm{C}\right)$ Tris-buffered ammonium chloride lysis buffer was added for lysis of red blood cells, and samples were incubated for $10 \mathrm{~min}$ at $37^{\circ} \mathrm{C}$. After centrifugation, 2 washes with PBS $(300 \times g, 7 \mathrm{~min}$, room temperature $)$ were performed and cell pellets were resuspended in Buffer RLT (Qiagen, Venlo, the Netherlands) and frozen at $-80^{\circ} \mathrm{C}$. Gene expression analysis from frozen cell lysates was performed using the nCounter Analysis System (Nanostring, Seattle, WA). This technology used molecular barcodes on gene sequence-specific probes and single molecule imaging to count RNA copies. This allowed the analysis of multiple genes from the same sample (multiplexing) using a set of probes with distinct barcodes called a CodeSet. The RNA samples were hybridized with a CodeSet consisting of probes specific for the following 16 genes: cytokines [IL2, IL4, IL6, IL10, IL12A, IL17A, IL22, IFNG, tumor necrosis factor $(T N F)]$, cytokine receptors (IL2RA, IL23R), costimulatory molecules $[C D 40, C D 40 L, C T L A 4$, programmed cell death protein 1 (PDCD1)], and effector molecules [perforin (PRF1)].
For analysis, the raw data were imported into nSolver Analysis Software version 2.5 (http://www.nanostring .com/products/nSolver) and underwent the software's sample quality control routine set to the following criteria: (1) imaging: fields of view registration $<75 \%$; (2) binding density outside the 0.05 to 2.25 range; (3) positive control linearity: positive control $\mathrm{R}^{2}$ value $<0.95$; and (4) positive control limit of detection: $0.5 \mathrm{fM}$ positive control $\leq 2 \mathrm{SD}$ above the mean of the negative controls. All samples passed the quality control routine. Background subtraction was performed by subtracting the geometric mean of 8 internal negative controls from each sample. Positive control normalization was performed using the geometric mean of 6 internal positive controls to compute the normalization factor. The normalization factor of all samples was inside the 0.15 to 15 range.

Reference gene normalization was performed using the geometric mean of counts for the reference genes ribosomal protein L15 (RPL15), $\beta$-glucuronidase $(G U S B)$, and tyrosine 3-monooxygenase/tryptophan 5 -monooxygenase activation protein zeta ( $Y W H A Z$ ). The average of these geometric means across all lanes was used as the reference against which each lane was normalized. A normalization factor was then calculated for each of the lanes based on the geometric mean of counts for the reference genes in each lane relative to the average geometric mean of counts for the reference genes across all lanes. This normalization factor was then used to adjust the counts for each gene target and controls in the associated lane. The normalization factor of all samples was inside the 0.1 to 30 range.

\section{Mammary Gland Ultrasound Scanning}

Ultrasound scanning of the mammary gland was conducted on heifer calves as previously described (Molenaar et al., 2013). Briefly, the heifer calves were restrained in a mobile head bail, with access to each of the 4 quarters of the mammary gland at d 100. Foodgrade oil was applied to the scan site to ensure good acoustic coupling. The ultrasound probe (M-Turbo with $\mathrm{C} 60 \mathrm{x} / 5.2-\mathrm{MHz}$ transducer; Sonosite USA, Bothell, WA) was applied successively beside each teat and rotated until the parenchymal tissue and fat pad were observed in the ultrasound image, and the image was captured and transferred to a computer. After size adjustment to match the image scan depth (usually 6.6 $\mathrm{cm}$ ), captured images were manually and independently scored by 2 operators for size, mammary composition, and confidence in the operators' score of the images using a ruler to measure gland diameter in centimeters. One operator scored mammary size on estimated mam- 
mary parenchyma, and the other operator included all visible fat pad and parenchyma (i.e., total mammary mass).

\section{Statistical Analyses}

For all parameters, pen was used as an experimental unit. Pen intake (solid feed, total intake of energy and nutrients), BW gain, and feed efficiency were analyzed separately for the 3 periods ( $0-56 \mathrm{~d}$ from start to earlier weaning, 57-100 d from the end of milk weaning for the earlier-weaned group to the end of the experiment, and 0-100 d overall from the start to the end of the study) using ANOVA in GenStat (18th ed.; VSN International, Hemel Hempstead, UK). Pen was used as a random term for testing fixed effects of weaning method, sex, and their interaction.

The gain in various body and skeletal parameters (heart girth, body barrel, body length, and withers height) was calculated for each calf and averaged by pen for each of the 3 periods (0-49 d from the start of the study to the beginning of earlier weaning, 50-100 d from the beginning of earlier weaning to the end of the study, and 0-100 d overall from the start to end of the study). Skeletal growth parameters and selected blood parameters measured at d 49 and 84 were analyzed using ANOVA in GenStat (18th ed.; VSN International), where pen was used as a random term for testing fixed effects of weaning method, sex, and their interaction. For the analysis of mammary gland ultrasonography data on heifers, the average score over the 4 quarters was calculated and analyzed with ANOVA to compare the effect of weaning age with pen as a random factor.

Body weights during the study were analyzed considering pen as an experimental unit. The $\mathrm{lm}$ function in $\mathrm{R}$ version 3.4.2 was used to generate the model Sum of Body Weight (pen) $\sim$ Sex $\times$ Weaning age $\times$ Week . This model was evaluated using the qqPlot function of the car $\mathrm{R}$ package version 2.1-5 (Fox and Monette, 2002), the plotNormalHistogram function of the $R$ package rcompanion version 1.10.1 (Mangiafico, 2018), and plotting the fitted and residual values. The overall ANOVA was performed using the ANOVA function of the car $\mathrm{R}$ package version 2.1-5. The means and $95 \%$ confidence interval plot were produced using the ggplot2 $\mathrm{R}$ package version 2.2.1 (Wickham, 2016).

Clostridium-specific antibody titers in blood serum were analyzed using ANOVA in GenStat (18th ed.; VSN International), where pen was used as a random term for testing fixed effects of weaning method, sex, and their interaction. The normalized gene expression RNA copy number in unstimulated cells was averaged by pen and loaded into $\mathrm{R}$ version 3.4.2 (R Core Team, 2018) for analysis. The permutation test for linear model (lmPerm package version 2.1.0; Wheeler and Torchiano, 2010) was used to perform permutation ANOVA on each studied gene with the following formula: average pen gene expression $\sim \operatorname{sex} \times$ weaning age. Permutation ANOVA was used due to the counts of one or both of the factors for some genes not being normally distributed where others were, making a global transformation such as logarithms inappropriate given that the genes were to be compared in a consistent manner. Vaccine efficiency test antibody titer data were transformed $(\log 10)$ and analyzed using ANOVA in GenStat (18th ed.; VSN International), where pen was used as a random term for testing fixed effects of weaning method, sex, and their interaction.

\section{RESULTS AND DISCUSSION}

\section{Feed Intake}

Intake of CMR, solid feed (FiberStart), and total nutrients (solid plus liquid feed) for each period of the experiment is presented in Table 3. The effect of sex and the interaction between weaning age and sex were not significant $(P>0.05)$ for intake parameters. Calves in both weaning groups consumed all allocated allowance of CMR during the study. Solid feed DMI was similar between earlier- and later-weaned calves for the first $56 \mathrm{~d}$ of the study. Solid feed intake increased rapidly during weaning (d 50 and 56) in earlier-weaned calves, and they consumed more solid feed DM during the second half of the experiment (d 57 to 100), and thus had greater overall solid feed DMI, compared with the later-weaned calves. An inverse relationship between milk and solid feed intake in calves has been demonstrated in older (Kertz et al., 1979) and more recent (Sweeney et al., 2010) studies. Calves start consuming measurable amounts of solid feed at about $14 \mathrm{~d}$ of age, and intake increases rapidly with the reduction and withdrawal of CMR (Khan et al., 2011). Similar to previous studies (Sweeney et al., 2010; Eckert et al., 2015; de Passillé and Rushen, 2016), in the current study, earlier-weaned calves had greater solid feed intake compared with late-weaned calves. It is important to mention that solid feed used in the previous studies was primarily grain-based concentrates (e.g., pelleted, mash, or textured calf starter), whereas in the current study earlier-weaned calves substituted CMR by consuming a significant amount of forage from d 49 (with the start of CMR reduction) to 100.

Total (liquid plus solid feed) DMI, CP intake, and ME intake were similar between both groups for the first 56 d. Calves in both groups also consumed similar amounts of total DM between d 56 and 100 and over the entire experiment (d 0 to 100). This indicates that earlier- 
Table 3. Pen feed intake, BW gain, and feed efficiency of heifer and bull calves reared on FiberStart ${ }^{1}$ as the only solid feed source for $100 \mathrm{~d}$ and fed calf milk replacer (CMR; AnCalf ${ }^{2}$ ) for either $56 \mathrm{~d}$ (earlier weaned) or $91 \mathrm{~d}$ (later weaned) ${ }^{3}$

\begin{tabular}{|c|c|c|c|c|c|c|c|c|}
\hline \multirow[b]{2}{*}{ Parameter $^{4}$} & \multicolumn{2}{|c|}{ Earlier weaned $^{5}$} & \multicolumn{2}{|c|}{ Later weaned ${ }^{6}$} & \multirow[b]{2}{*}{$\mathrm{SED}^{7}$} & \multicolumn{3}{|c|}{$P$-value } \\
\hline & Bulls & Heifers & Bulls & Heifers & & $\begin{array}{l}\text { Weaning } \\
\text { age }\end{array}$ & Sex & $\begin{array}{l}\text { Weaning } \\
\text { age } \times \text { sex }\end{array}$ \\
\hline \multicolumn{9}{|c|}{ CMR DMI (kg/pen) } \\
\hline $0-56 \mathrm{~d}$ & 174 & 174 & 175 & 187 & & & & \\
\hline $57-100 \mathrm{~d}$ & 0 & 0 & 96 & 104 & & & & \\
\hline $0-100 \mathrm{~d}$ & 174 & 174 & 272 & 291 & & & & \\
\hline $57-100 \mathrm{~d}$ & 561 & 571 & 454 & 465 & 29.3 & 0.01 & 0.60 & 0.98 \\
\hline $0-100 \mathrm{~d}$ & 679 & 713 & 567 & 590 & 40.4 & 0.01 & 0.34 & 0.85 \\
\hline \multicolumn{9}{|c|}{ Total DMI ${ }^{8}$ (kg/pen) } \\
\hline $0-56 \mathrm{~d}$ & 292 & 315 & 288 & 312 & 15.4 & 0.73 & 0.06 & 0.96 \\
\hline $57-100 \mathrm{~d}$ & 561 & 571 & 550 & 569 & 31.2 & 0.79 & 0.52 & 0.86 \\
\hline $0-100 \mathrm{~d}$ & 853 & 887 & 839 & 881 & 45.0 & 0.76 & 0.26 & 0.89 \\
\hline \multicolumn{9}{|c|}{ Total NDF intake (kg/pen) } \\
\hline $57-100 \mathrm{~d}$ & 5,213 & 5,312 & 6,237 & 6,486 & 318 & 0.01 & 0.45 & 0.74 \\
\hline $0-100 \mathrm{~d}$ & 9,944 & 10,256 & 10,939 & 11,554 & 498 & 0.01 & 0.21 & 0.67 \\
\hline \multicolumn{9}{|c|}{ Total CP intake ${ }^{1}(\mathrm{~kg} / \mathrm{pen})$} \\
\hline $0-56 \mathrm{~d}$ & 69 & 73 & 68 & 74 & 3 & 0.90 & 0.06 & 0.81 \\
\hline $57-100 \mathrm{~d}$ & 107 & 110 & 113 & 116 & 6 & 0.15 & 0.50 & 0.82 \\
\hline $0-100 \mathrm{~d}$ & 176 & 183 & 181 & 191 & 9 & 0.33 & 0.24 & 0.81 \\
\hline \multicolumn{9}{|c|}{ BW gain (kg/pen) } \\
\hline $0-56 \mathrm{~d}$ & 177 & 178 & 175 & 197 & 13.2 & 0.29 & 0.24 & 0.28 \\
\hline $57-100 \mathrm{~d}$ & 143 & 142 & 178 & 188 & 15.6 & 0.01 & 0.70 & 0.62 \\
\hline $0-100 \mathrm{~d}$ & 320 & 320 & 353 & 385 & 26.2 & 0.01 & 0.40 & 0.40 \\
\hline \multicolumn{9}{|c|}{ Feed efficiency (BW gain/DMI) } \\
\hline $0-56 \mathrm{~d}$ & 0.60 & 0.56 & 0.62 & 0.63 & 0.024 & 0.01 & 0.54 & 0.25 \\
\hline $57-100 \mathrm{~d}$ & 0.26 & 0.25 & 0.33 & 0.33 & 0.023 & 0.01 & 0.65 & 0.81 \\
\hline $0-100 \mathrm{~d}$ & 0.37 & 0.36 & 0.43 & 0.43 & 0.210 & 0.01 & 0.74 & 0.56 \\
\hline
\end{tabular}

${ }^{1}$ Modified biofermentation alfalfa high-nutritional fiber (Medicago sativa) treated with Xanotyde (Fiber Fresh Feeds Ltd., Reporoa, New Zealand). ${ }^{2}$ NZAgbiz, Temuka, New Zealand.

${ }^{3} \mathrm{n}=4$ pens of each sex per weaning group with 5 calves in each pen.

${ }^{4}$ Pen intake (solid feed, total, energy, and nutrients), BW gain, and feed efficiency presented for 3 periods $(0-56 \mathrm{~d}=$ from start to earlier weaning; $57-100 \mathrm{~d}=$ from the end of earlier weaning to the end of the experiment; $0-100 \mathrm{~d}=$ overall from the start to the end of the study).

${ }^{5}$ Earlier-weaned calves were fed CMR until d 49 and gradually weaned by d 56.

${ }^{6}$ Later-weaned calves were fed CMR until d 84 and gradually weaned by d 91.

${ }^{7}$ Standard errors of differences of means.

${ }^{8}$ Total amount of DM and nutrients from both solid (FiberStart) and liquid (CMR) feeds.

weaned calves were able to compensate for the loss of CMR DMI from d 56 to 100 by increasing forage intake. However, despite having similar total DM throughout the study, BW gain was lower in earlier-weaned calves compared with later-weaned calves, indicating that earlier-weaned calves were unable to fully compensate the loss of energy or nutrients from CMR. Neutral detergent fiber intake was similar between groups for the first 56 d, but earlier-weaned calves consumed $25 \%$ more NDF between d 56 and 100, resulting in 17\% greater NDF intake over the entire experiment. Early-weaned calves were able to compensate for reduced $\mathrm{CP}$ intake from CMR by increasing forage intake between $\mathrm{d} 56$ and 100 and had CP intake similar to that of later-weaned calves during the experiment. However, ME intakes were $20 \%$ greater in later-weaned calves compared with earlier-weaned calves from d 56 to 100 . Over the entire study (0 to $100 \mathrm{~d}$ ), the later-weaned calves consumed $13.2 \%$ more ME compared with earlier-weaned calves. Similar results were reported previously, where calves fed pelleted or textured starter diets were weaned at different ages (Sweeney et al., 2010). It has been suggested that provision of low milk volume and earlier weaning systems could compromise the supply of nutrients to developing calves fed concentrate diets with or without forage (Khan et al., 2016). Different management (Costa et al., 2016), milk feeding, and weaning strategies (Khan et al., 2011, 2016) are proposed to 
stimulate intake of concentrates and therefore growth around weaning in calves. However, little information exists on calves weaned on forage-based diets, and, as such, the interaction between milk feeding and weaning age on calf performance on forage-based diets warrants further investigation.

\section{Growth Performance and Feed Efficiency}

To the best of our knowledge, in the last few decades, this is the first study demonstrating that dairy calves can be artificially reared and weaned successfully using forage as the only solid feed on a restricted milk supply. However, as has been reported with grain-based starter feeds for calves (Sweeney et al., 2010; Eckert et al., 2015), the duration of CMR feeding affects calf growth performance at least until $100 \mathrm{~d}$.

Body weight gain of calves is presented in Table 3 . The effect of sex and interaction between weaning age and sex were not significant for BW gain. Body weight gain was similar for calves in both weaning treatments for the first $56 \mathrm{~d}$; however, later-weaned calves gained $16.3 \%$ more live weight than earlier-weaned calves over the entire study. A weaning age $\times$ time interaction was evident for live weight whereby a divergence was observed from wk 11, with later-weaned calves maintaining a greater live weight than earlier-weaned calves, independent of sex, until the end of the trial at 14 wk (Figure 1). Live weight of earlier-weaned calves was lower than that of later-weaned calves (104 vs. 121 $\pm 1.3 \mathrm{~kg} /$ calf; $P<0.01$ ) at the end of the experiment. Skeletal growth and body barrel parameters are presented in Table 4 . There was no weaning age $\times$ sex interaction for any of the body dimension parameters measured $(P>0.05)$. Similarly, there was no effect of sex on skeletal parameters except body barrel, which was greater in males compared with females between 50 and $100 \mathrm{~d}$ of the study. Calves in both weaning groups had similar gain in skeletal growth and body barrel between $\mathrm{d} 0$ and 49 of the study. Later-weaned calves had greater gain in heart girth and withers height than earlier-weaned calves between d 50 and 100 and overall during the study. Body length gain between d 50 and 100 was similar for calves in each weaning group; however, later-weaned calves had greater overall gain in body length during the entire study. Later-weaned calves had greater overall gain in body barrel compared with those weaned earlier. Feed efficiency (BW gain/ total feed DMI) was greater in later-weaned calves compared with earlier-weaned calves throughout the study but was not different between the sexes, nor was a weaning age $\times$ sex interaction evident (Table 3 ).

Greater BW gain, body dimensions, and better feed efficiency in calves weaned at 91 versus $56 \mathrm{~d}$ of age are the function of a greater supply of nutrients and energy from CMR (Table 3). Previously, Hill et al. (2010) reported that feeding greater quantities of CMR before weaning could delay rumen development, depressing solid feed consumption around weaning. In the current study, all calves received a moderate amount of CMR (700 g/calf per day) to stimulate solid feed consumption and enable earlier weaning. However, calves weaned off CMR at $49 \mathrm{~d}$ were unable to fully compensate for the loss of energy from CMR by substituting with forage to support growth between d 56 and 100 of the study. Recovery in CP consumption compared with ME intake between 56 and $100 \mathrm{~d}$ indicates the importance of the energy supply compared with protein for growth in early-weaned calves. The failure of earlier-weaned calves to recover their energy intake similar to laterweaned calves is consistent with earlier findings (Sweeney et al., 2010; Eckert et al., 2015; Berends et al., 2018) and collectively reinforces the need to revisit and refine methods to improve the weaning transition from liquid to solid diets in calves. It is important to mention that forages greatly vary in their physical and chemical properties and are generally less energy dense than concentrate calf starters (Khan et al., 2016). Therefore, finding ways (e.g., weaning methods) to maintain energy supply for growth during the weaning transition become more significant in forage-fed calves than in concentrate-fed calves. Further, it is important to note that in the current study all calves were fed forage as the only solid feed; therefore, both BWG and feed efficiency results should be treated with caution due to likely differences in the gut fill between earlier- and later-weaned calves.

\section{Plasma Metabolites}

Serum metabolite profiles of calves are presented in Table 5. The effect of sex and the interaction between weaning age and sex were not significant for the blood metabolites except for total protein at d 49 of the study. A weaning age $x$ sex interaction was evident whereby later-weaned bull calves had lower serum total protein compared with later-weaned heifers at $49 \mathrm{~d}$, whereas no sex effects on total serum protein were observed in early-weaned calves. Weaning age had no effect on serum concentrations of metabolites at d 49 of the study. At d 84 , there was no effect of weaning age on glucose, nonesterified fatty acids, or triglycerides, indicating similar energy status in both groups. Later-weaned calves tended to have lower levels of BHB, indicating greater metabolic activity of the rumen wall due to increased intake of solid feed and subsequent rumen fermentation in earlier-weaned calves (Quigley et al., 1991). However, the greater metabolic activity of the rumen wall in 


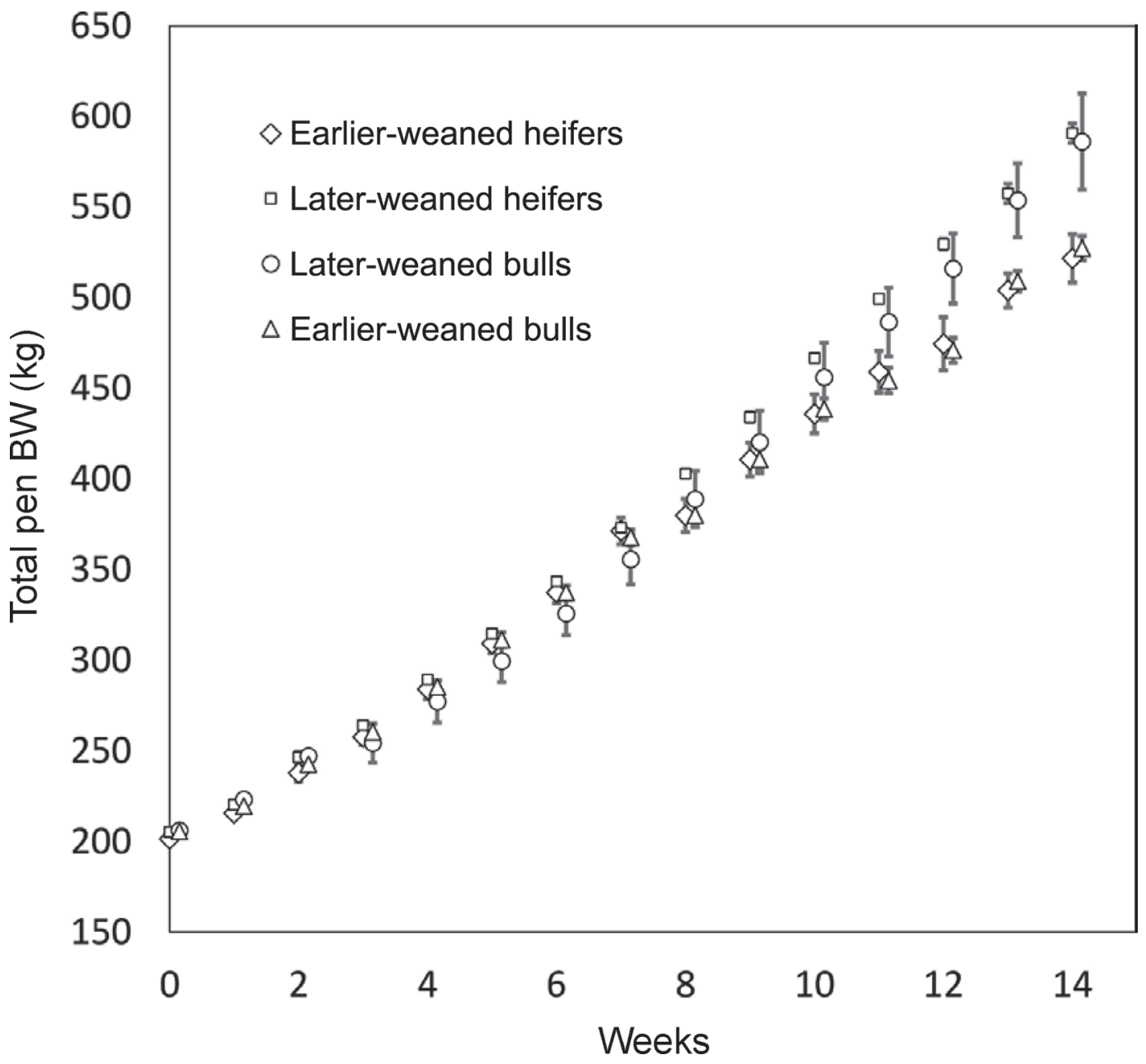

Figure 1. Pen total weekly live weights (mean $\pm 95 \%$ CI) of heifer and bull calves reared on FiberStart [modified biofermentation alfalfa high-nutritional fiber (Medicago sativa) treated with Xanotyde (Fiber Fresh Feeds Ltd., Reporoa, New Zealand)] as the only solid feed for $100 \mathrm{~d}$ and fed calf milk replacer (CMR; NZAgbiz, Temuka, New Zealand) for either $56 \mathrm{~d}$ (earlier weaned) or $91 \mathrm{~d}$ (later weaned). Earlier-weaned calves were fed CMR until d 49 and gradually weaned by d 56, and later-weaned calves were fed CMR until d 84 and gradually weaned by d 91 . Pen (4 pens/treatment) $=5$ calves of the same sex in a pen. Week: $P<0.01$; sex: $P<0.01$; weaning age: $P<0.01$; sex $\times$ weaning age: $P<0.02$; sex $\times$ week: $P<0.99$; weaning age $\times$ week: $P<0.01$; sex $\times$ weaning age $\times$ week: $P<0.99$. Treatment means for earlier- and later-weaned calves tend to differ for wk $11(P<0.08)$ and differ at wk $12(P<0.01), 13(P<0.01)$, and $14(P<0.01)$.

earlier-weaned calves was not sufficient to increase nutrient supply to compensate the loss of CMR nutrients to maintain growth equivalent to that of later-weaned calves. Later-weaned calves had lower levels of total serum protein and BUN, which is indicative of lower feed protein degradation in the rumen and is consistent with increased rumen fermentation activity. In general, rumen ammonia- $\mathrm{N}$ production that exceeds the utilization capacity of ruminal microbes will be transported to the liver via blood circulation and converted to urea, which is either recycled or excreted in urine. Therefore, greater solid feed intake by the earlier-weaned calves, while accelerating rumen wall metabolic development, may also increase the metabolic cost associated with hepatic urea production if a significant excess of RDP is present in the diet (Berends et al., 2014).

\section{Immune Function}

Immune function of heifer calves has been shown to be improved by a greater nutrient and energy supply (Khan et al., 2011). Conversely, nutritional deficiency can depress immune function and thus increase susceptibility to diseases in calves (Nonnecke et al., 2003). Weaning calves earlier or abruptly could compromise the supply of nutrients to young calves after weaning (Khan et al., 2011; Eckert et al., 2015; de Passillé and Rushen, 2016). Therefore, in the current study, 
Table 4. Skeletal growth and body barrel (an indicator of gut fill) of heifer and bull calves reared on FiberStart ${ }^{1}$ as the only solid feed and fed calf milk replacer (CMR; AnCalf ${ }^{2}$ ) for either $56 \mathrm{~d}$ (earlier weaned) or $91 \mathrm{~d}$ (later weaned) ${ }^{3}$

\begin{tabular}{|c|c|c|c|c|c|c|c|c|}
\hline \multirow[b]{2}{*}{ Parameter $^{4}$} & \multicolumn{2}{|c|}{ Earlier weaned $^{5}$} & \multicolumn{2}{|c|}{ Later weaned ${ }^{6}$} & \multirow[b]{2}{*}{$\mathrm{SED}^{7}$} & \multicolumn{3}{|c|}{$P$-value } \\
\hline & Bulls & Heifers & Bulls & Heifers & & $\begin{array}{l}\text { Weaning } \\
\text { age }\end{array}$ & Sex & $\begin{array}{l}\text { Weaning } \\
\text { age } \times \text { sex }\end{array}$ \\
\hline \multicolumn{9}{|c|}{ Heart girth $(\mathrm{cm} /$ calf $)$} \\
\hline $0-49 \mathrm{~d}$ & 17.6 & 17.2 & 17.8 & 17.6 & 1.0 & 0.72 & 0.66 & 0.84 \\
\hline $50-100 \mathrm{~d}$ & 10.2 & 10.3 & 14.3 & 13.1 & 1.5 & 0.01 & 0.59 & 0.54 \\
\hline $0-100 \mathrm{~d}$ & 27.8 & 27.5 & 32.1 & 30.7 & 1.1 & 0.01 & 0.46 & 0.51 \\
\hline \multicolumn{9}{|c|}{ Body barrel (cm/calf) } \\
\hline $50-100 \mathrm{~d}$ & 27.7 & 25.1 & 30.3 & 26.8 & 1.7 & 0.09 & 0.02 & 0.72 \\
\hline $0-100 \mathrm{~d}$ & 63.0 & 58.7 & 65.6 & 61.9 & 1.9 & 0.04 & 0.01 & 0.83 \\
\hline \multicolumn{9}{|c|}{ Body length (cm/calf) } \\
\hline $0-49 \mathrm{~d}$ & 16.8 & 15.9 & 19.2 & 17.2 & 1.6 & 0.12 & 0.23 & 0.64 \\
\hline $50-100 \mathrm{~d}$ & 12.5 & 14.3 & 14.0 & 15.4 & 1.5 & 0.27 & 0.16 & 0.88 \\
\hline $0-100 \mathrm{~d}$ & 29.3 & 30.2 & 33.2 & 32.7 & 1.8 & 0.02 & 0.89 & 0.57 \\
\hline \multicolumn{9}{|c|}{ Withers height $(\mathrm{cm} /$ calf $)$} \\
\hline
\end{tabular}

${ }^{1}$ Modified biofermentation alfalfa high-nutritional fiber (Medicago sativa) treated with Xanotyde (Fiber Fresh Feeds Ltd., Reporoa, New Zealand). ${ }^{2}$ NZAgbiz, Temuka, New Zealand.

${ }^{3} \mathrm{n}=4$ pens of each sex per weaning group with 5 calves in each pen.

${ }^{4}$ The differences in skeletal parameters and body barrel were calculated for each calf and averaged by pen for each of the 3 periods $(0-49 \mathrm{~d}=$ from the start of the study to the beginning of earlier weaning; $50-100 \mathrm{~d}=$ from the beginning of earlier weaning to the end of the study; $0-100$ $\mathrm{d}=$ overall from the start to the end of the study).

${ }^{5}$ Earlier-weaned calves were fed CMR until d 49 and gradually weaned by d 56.

${ }^{6}$ Later-weaned calves were fed CMR until d 84 and gradually weaned by d 91.

${ }^{7}$ Standard errors of differences of means.

Table 5. Selected blood metabolites (mmol/L, unless otherwise noted) of heifer and bull calves reared on FiberStart ${ }^{1}$ as the only solid feed and fed calf milk replacer (CMR; AnCalf ${ }^{2}$ ) for either $56 \mathrm{~d}$ (earlier weaned) or $91 \mathrm{~d}$ (later weaned) ${ }^{3}$

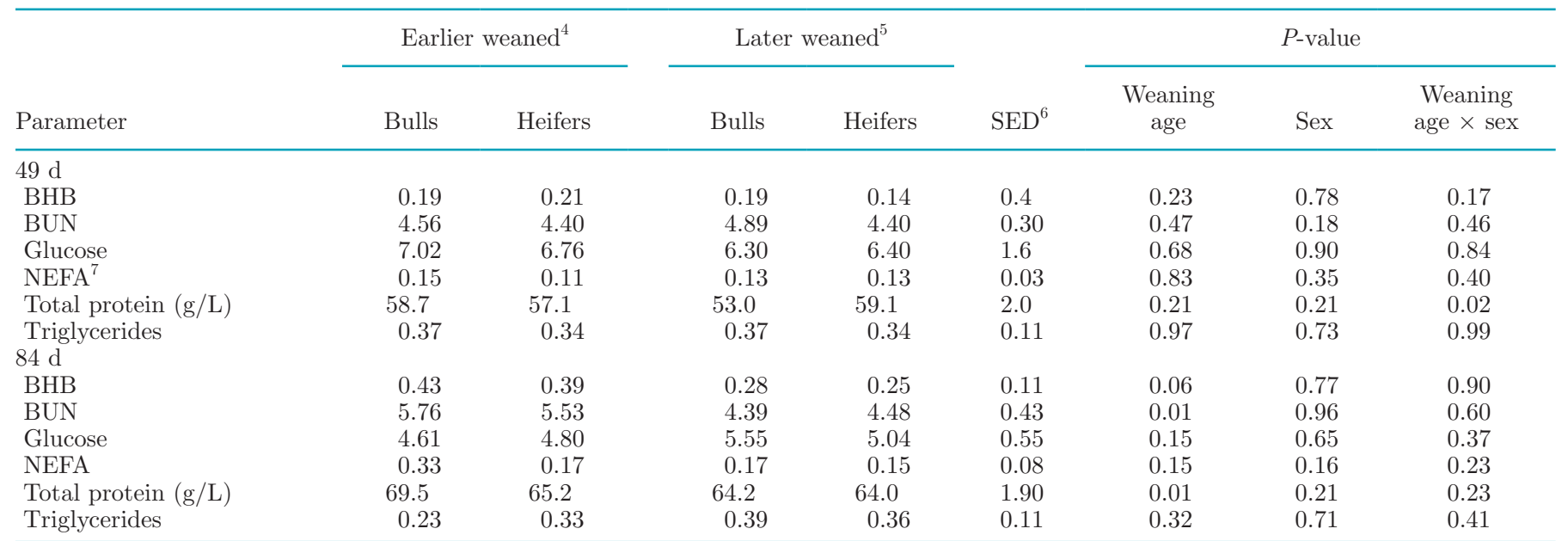

${ }^{1}$ Modified biofermentation alfalfa high-nutritional fiber (Medicago sativa) treated with Xanotyde (Fiber Fresh Feeds Ltd., Reporoa, New Zealand).

${ }^{2}$ NZAgbiz, Temuka, New Zealand.

${ }^{3} \mathrm{n}=4$ pens of each sex per weaning group with 5 calves in each pen.

${ }^{4}$ Earlier-weaned calves were fed CMR until d 49 and gradually weaned by d 56.

${ }^{5}$ Later-weaned calves were fed CMR until d 84 and gradually weaned by d 91 .

${ }^{6}$ Standard errors of differences of means.

${ }^{7} \mathrm{NEFA}=$ nonesterified fatty acids. 
the influence of expected differences in nutrient and energy intake between early- and late-weaned calves on their humoral immune response was investigated by measuring the antibody response to a vaccine. The anticlostridium vaccine induced clostridium-specific antibody production in all animals. Prevaccination clostridium antibody levels (measured in 1:200 diluted serum) were at an optical density of $0.454 \pm 0.268$, which increased to $1.60 \pm 0.152$ after vaccination $(P<$ $0.01)$. This increase in antigen-specific antibodies is the desired result after vaccination (Janeway et al., 2001). Weaning age, sex, or the interaction between weaning age and sex did not influence the vaccination outcome (data not presented).

To investigate the effect of weaning age on cellmediated immunity, several genes were selected for expression analysis from blood samples for their roles in T lymphocyte function-namely, cytokines (IL2, IL4, IL6, IL10, IL12A, IL17A, IL22, IFNG, TNF), cytokine receptors (IL2RA, IL23R), T lymphocyte costimulatory molecules (CD4O,CD4OL, CTLA 4, PDCD1), and effector molecules (PRF1). All 16 investigated genes were expressed in all animals (Table 6 ). Expression varied within a range expected for an outbred population and was comparable with reports from adult dairy cows
(Heiser et al., 2015). There was a weaning age $\times$ sex interaction for $I L 10$ whereby later-weaned heifers had greater expression than later-weaned bulls, whereas no differences were observed between early-weaned heifer and bull calves; IL10 is the gene for IL-10, which is involved in regulating inflammatory processes (Sabat, 2010). A weaning age $\times$ sex interaction was also observed by PRF1 whereby later-weaned heifers had lower levels of expression relative to later-weaned bulls, whereas the opposite effect was observed in the earlier-weaned group; PRF1 encodes for perforin-1, a cytolytic enzyme expressed by $\mathrm{T}$ lymphocytes and NK cells (Trapani, 1995). No other effects of weaning age, sex, or their interaction were observed for any of the other cytokines evaluated. It is important to note that the fold difference in RNA copy number is small $(<2)$ for both genes and therefore cannot be interpreted as reflecting a functional difference or having biological relevance, particularly in the context of the lack of differences in the expression of the other cytokines.

In conclusion, weaning age did not affect the antibody response to anticlostridial vaccine. Further, the expression of genes related to cell-mediated immunity, particularly T lymphocyte function, was not affected by weaning calves at different ages. These results are con-

Table 6. Gene expression in blood cells from heifer and bull calves reared on FiberStart ${ }^{1}$ as the only solid feed for $100 \mathrm{~d}$ and fed calf milk replacer (CMR; AnCalf ${ }^{2}$ ) for either $56 \mathrm{~d}$ (earlier weaning) or $91 \mathrm{~d}$ (later weaning) ${ }^{3}$

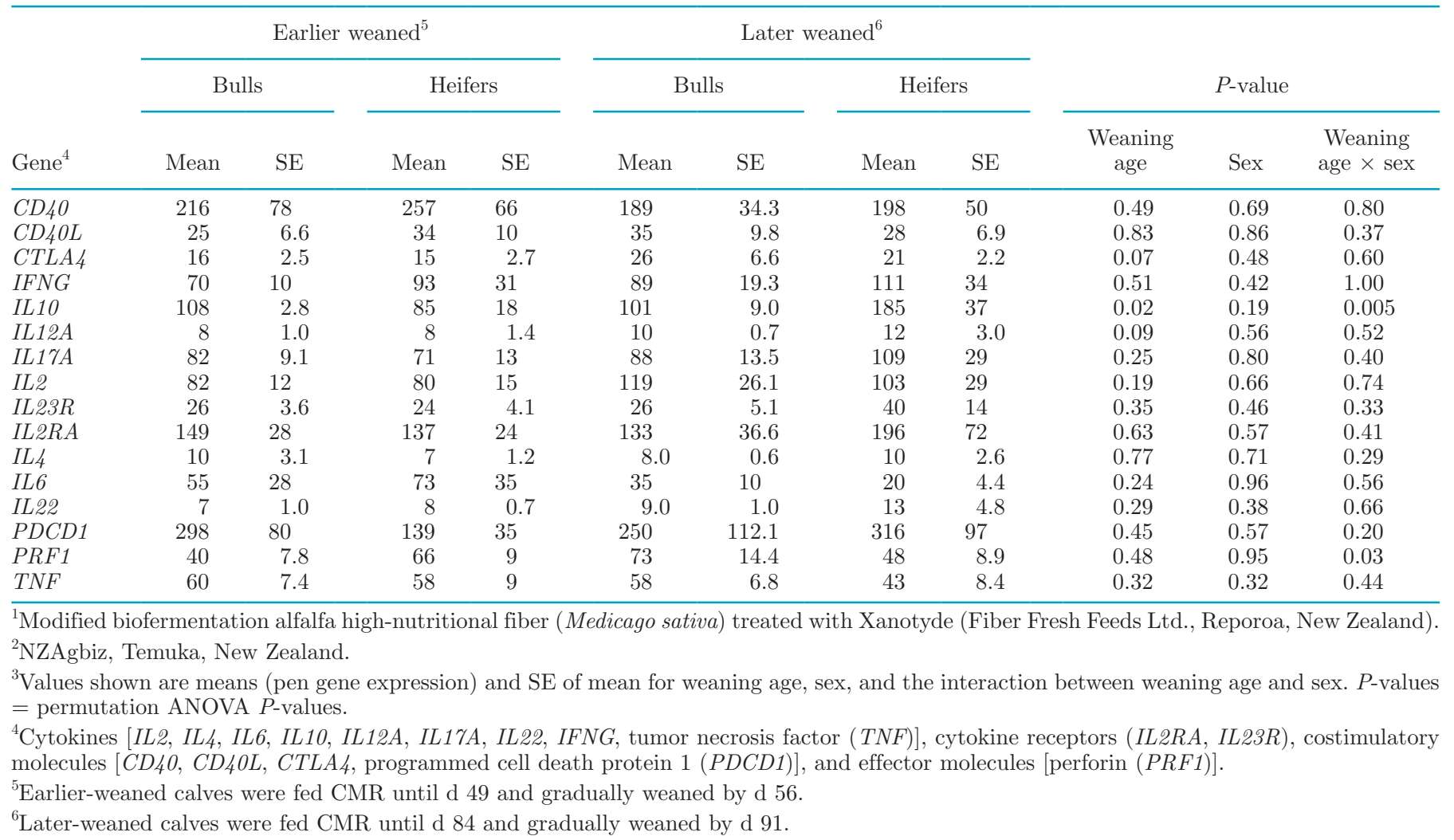


sistent with the observation of Nonnecke et al. (2003) in which functional aspects of the immune system were largely unaffected by the amount of milk or CMR fed to calves. The results of the current study indicate that at least within the parameters measured, the duration of CMR feeding and resulting difference in energy and nutrient intake between early- and later-weaned calves (Table 3) had little effect on their immune system.

\section{Mammary Gland Development}

Mammary gland size (parenchyma and total fat) at d 100 was $5 \%$ lower in earlier- versus later-weaned calves (4.91 vs. $5.22 \mathrm{~cm} ; \mathrm{SE}=0.103 ; P=0.02)$. This indicates that increased CMR consumption increased mammary mass, but there was no effect of the duration of CMR feeding on parenchyma mass (4.5 vs. 4.4 $\mathrm{cm} ; \mathrm{SE}=0.15 ; P=0.40)$. These results reflect the observations of Meyer et al. (2006) in which elevated nutrient intake was not associated with changes in total parenchymal mass but rather an increase in mammary fat pad weight. It has been suggested that a larger fat pad is beneficial because the ultimate number of epithelial cells within the mammary gland is dictated by the amount of adipose tissue in the mammary fat pad (Hovey et al., 1999). Doubling the nutrient intake of CMR alters mRNA expression across several pathways and molecular functions, indicating that the mammary transcriptome is responsive to long-term changes in nutrient supply (Piantoni et al., 2012), which may contribute to the observed enhanced growth of the mammary fat pad in response to the enhanced nutrient intake from CMR (Daniels et al., 2009). The effect of extending the period of CMR feeding from 49 to $84 \mathrm{~d}$ on the mammary transcriptome was not investigated in the present study but warrants further investigation due to the potential for the quality and quantity of feed offered to calves during preweaning to influence the development of the mammary gland (Geiger et al., 2016) and future milk production (Chester-Jones et al., 2017).

\section{CONCLUSIONS}

Dairy calves can be artificially reared and weaned successfully on conserved forage (FiberStart) as the only solid feed for $100 \mathrm{~d}$. Age at weaning off CMR (56 vs. $91 \mathrm{~d}$ ) affected the energy intake, BW gain, and mammary gland growth but not immune function of calves. Calves weaned at d 56 compensated for the loss of CMR DM and CP by increasing forage intake by $\mathrm{d}$ 100 , but calves were unable to compensate for the loss of energy from CMR during the same period. Lower total energy availability to earlier-weaned calves from d
56 to 100 resulted in $16 \%$ lower BW gain and $5 \%$ lower total mammary gland growth compared with calves weaned at d 91. A moderate milk allowance used in this study was selected to encourage solid feed intake. The animal responses to feeding higher levels of milk may differ; however, this would require further research. The results of this study provide knowledge that supports the potential of grain-free alternative rearing systems in which a whole-life grain-free diet is desired to meet market requirements. The implications of these differences in growth for lifetime productivity also warrant further investigation.

\section{ACKNOWLEDGMENTS}

The authors gratefully acknowledge Frederik Knol, German Molano, and Taina Silvestre (all from AgResearch Grasslands, Palmerston North, New Zealand) for support with calf measurements and blood sampling and Phillip Weir (AgResearch, Hamilton, New Zealand) for support with contracting. We are also highly grateful to the late John Koolaard from AgResearch Grasslands (Palmerston North, New Zealand) for his contribution to the experimental design of the animal trial and preliminary data analysis. This project was partially funded by the Callaghan Innovations-R \& D Growth Grant Programme (Wellington, New Zealand), Fiber Fresh Feed Ltd. (Reporoa, New Zealand), and the AgResearch PreSeed Fund (Hamilton, New Zealand); the authors thank these funding bodies for their support.

\section{REFERENCES}

Baldwin, R. L., K. R. McLeod, J. L. Klotz, and R. N. Heitmann. 2004. Rumen development, intestinal growth and hepatic metabolism in the pre- and postweaning ruminant. J. Dairy Sci. 87:E55-E65. https://doi.org/10.3168/jds.S0022-0302(04)70061-2.

Ballou, M. A. 2012. Immune responses of Holstein and Jersey calves during the preweaning and immediate postweaned periods when fed varying planes of milk replacer. J. Dairy Sci. 95:7319-7330. https://doi.org/10.3168/jds.2012-5970.

Berends, H., J. J. G. C. van den Borne, B. A. Røjen, J. van Baal, and W. J. J. Gerrits. 2014. Urea recycling contributes to nitrogen retention in calves fed milk replacer and low-protein solid feed. J. Nutr. 144:1043-1049. https://doi.org/10.3945/jn.114.191353.

Berends, H., M. Vidal, M. Terré, L. N. Leal, J. Martín-Tereso, and A. Bach. 2018. Effects of fat inclusion in starter feeds for dairy calves by mixing increasing levels of a high-fat extruded pellet with a conventional highly fermentable pellet. J. Dairy Sci. 101:1096210972. https://doi.org/10.3168/jds.2018-15116.

Cafe, L. M., D. W. Hennessy, H. Hearnshaw, S. G. Morris, and P. L. Greenwood. 2006. Influences of nutrition during pregnancy and lactation on birth weights and growth to weaning of calves sired by Piedmontese or Wagyu bulls. Aust. J. Exp. Agric. 46:245-255. https://doi.org/10.1071/EA05225.

Chester-Jones, H., B. J. Heins, D. Ziegler, D. Schimek, S. Schuling, B. Ziegler, M. B. de Ondarza, C. J. Sniffen, and N. Broadwater. 2017. Relationships between early-life growth, intake, and birth season 
with first lactation performance of Holstein dairy cows. J. Dairy Sci. 100:3697-3704.

Costa, J. H. C., M. A. G. von Keyserlingk, and D. M. Weary. 2016. Invited review: Effects of group housing of dairy calves on behavior, cognition, performance, and health. J. Dairy Sci. 99:2453-2467. https://doi.org/10.3168/jds.2015-10144.

Daniels, K. M., A. V. Capuco, M. L. McGilliard, R. E. James, and R. M. Akers. 2009. Effects of milk replacer formulation on measures of mammary growth and composition in Holstein heifers. J. Dairy Sci. 92:5937-5950. https://doi.org/10.3168/jds.2008-1959.

de Passillé, A. M., and J. Rushen. 2016. Using automated feeders to wean calves fed large amounts of milk according to their ability to eat solid feed. J. Dairy Sci. 99:3578-3583. https://doi.org/10 .3168/jds.2015-10259.

Eckert, E., H. E. Brown, K. E. Leslie, T. J. DeVries, and M. A. Steele. 2015. Weaning age affects growth, feed intake, gastrointestinal development, and behavior in Holstein calves fed an elevated plane of nutrition during the preweaning stage. J. Dairy Sci. 98:6315-6326. https://doi.org/10.3168/jds.2014-9062.

Foote, M. R., B. J. Nonnecke, D. C. Beitz, and W. R. Waters. 2007. High growth rate fails to enhance adaptive immune responses of neonatal calves and is associated with reduced lymphocyte viability. J. Dairy Sci. 90:404-417. https://doi.org/10.3168/jds.S0022 $-0302(07) 72641-3$.

https://doi.org/Fox, J., and G. Monette. 2002. An R and S-Plus Companion to Applied Regression. Sage, Thousand Oaks, CA.

Geiger, A. J., C. L. M. Parsons, and R. M. Akers. 2016. Feeding a higher plane of nutrition and providing exogenous estrogen increases mammary gland development in Holstein heifer calves. J. Dairy Sci. 99:7642-7653.

Heiser, A., A. McCarthy, N. Wedlock, S. Meier, J. Kay, C. Walker, M. A. Crookenden, M. D. Mitchell, S. Morgan, K. Watkins, J. J. Loor, and J. R. Roche. 2015. Grazing dairy cows had decreased interferon- $\gamma$, tumor necrosis factor, and interleukin-17, and increased expression of interleukin-10 during the first week after calving. J. Dairy Sci. 98:937-946. https://doi.org/10.3168/ jds.2014-8494.

Hill, T. M., H. G. Bateman, J. M. Aldrich, and R. L. Schlotterbeck. 2010. Effect of milk replacer program on digestion of nutrients in dairy calves. J. Dairy Sci. 93:1105-1115. https://doi.org/10.3168/ jds.2009-2458.

Hovey, R. C., T. B. McFadden, and R. M. Akers. 1999. Regulation of mammary gland growth and morphogenesis by the mammary fat pad: A species comparison. J. Mammary Gland Biol. Neoplasia 4:53-68.

Janeway, C. A., Jr., P. Travers, M. Walport, and M. J. Shlomchik. 2001. Immunobiology: The Immune System in Health and Disease. 5th ed. Garland Science, New York, NY.

Kertz, A. F., L. R. Prewitt, and J. P. Everett Jr.. 1979. An early weaning calf program: Summarization and review. J. Dairy Sci. 62:1835-1843. https://doi.org/10.3168/jds.S0022-0302(79)83508 $-0$.

Khan, M. A., A. Bach, D. M. Weary, and M. A. G. von Keyserlingk. 2016. Transitioning from milk to solid feed in dairy heifers. J. Dairy Sci. 99:885-902. https://doi.org/10.3168/jds.2015-9975.

Khan, M. A., D. M. Weary, and M. A. G. Von Keyserlingk. 2011. Effects of milk ration on solid feed intake, weaning, and performance in dairy heifers. J. Dairy Sci. 94:1071-1081. https://doi.org/10 .3168/jds.2010-3733.

Laarman, A. H., and M. Oba. 2011. Short communication: Effect of calf starter on rumen $\mathrm{pH}$ of Holstein dairy calves at weaning. J. Dairy Sci. 94:5661-5664. https://doi.org/10.3168/jds.2011-4273.

Mangiafico, S. 2018. rcompanion: Functions to support extension education program evaluation. The Comprehensive $\mathrm{R}$ Archive Net- work. Accessed June 15-21, 2018. https://CRAN.R-project.org/ package $=$ rcompanion .

Meyer, M. J., A. V. Capuco, D. A. Ross, L. M. Lintault, and M. E. Van Amburgh. 2006. Developmental and nutritional regulation of the prepubertal bovine mammary gland: II. Epithelial cell proliferation, parenchymal accretion rate, and allometric growth. J. Dairy Sci. 89:4298-4304. https://doi.org/10.3168/jds.S0022 -0302(06)72476-6.

Molenaar, A., S. R. Leath, G. Caja, H. V. Henderson, C. Cameron, M. Challies, K. Taukiri, T. Chikazhe, S. Kaumoana, B. Lannou, A. Dorleac, A. Guy, C. Gavin, and K. Singh. 2013. Development of ultrasound methodology to measure cow udder cistern storage capacity in the New Zealand pasture-fed context. Proc. N.Z. Soc. Anim. Prod. 73:114-116.

Nonnecke, B. J., M. R. Foote, J. M. Smith, B. A. Pesch, and M. E. Van Amburgh. 2003. Composition and functional capacity of blood mononuclear leukocyte populations from neonatal calves on standard and intensified milk replacer diets. J. Dairy Sci. 86:35923604. https://doi.org/10.3168/jds.S0022-0302(03)73965-4.

Piantoni, P., K. M. Daniels, R. E. Everts, S. L. Rodriguez-Zas, H. A. Lewin, W. L. Hurley, R. M. Akers, and J. J. Loor. 2012. Level of nutrient intake affects mammary gland gene expression profiles in preweaned Holstein heifers. J. Dairy Sci. 95:2550-2561. https://doi .org/10.3168/jds.2011-4539.

Quigley, J. D., III, L. A. Caldwell, G. D. Sinks, and R. N. Heitmann. 1991. Changes in blood glucose, non-esterified fatty acids, and ketones in response to weaning and feed intake in young calves. J. Dairy Sci. 74:250-257.

R Core Team. 2018. R: A language and environment for statistical computing. Version 3.4.2. R Foundation for Statistical Computing, Vienna, Austria.

Sabat, R. 2010. IL-10 family of cytokines. Cytokine Growth Factor Rev. 21:315-324. https://doi.org/10.1016/j.cytogfr.2010.11.001.

Soberon, F., and M. E. Van Amburgh. 2017. Effects of preweaning nutrient intake in the developing mammary parenchymal tissue. J. Dairy Sci. 100:4996-5004.

Sweeney, B. C., J. Rushen, D. M. Weary, and A. M. de Passillé. 2010. Duration of weaning, starter intake, and weight gain of dairy calves fed large amounts of milk. J. Dairy Sci. 93:148-152. https:/ /doi.org/10.3168/jds.2009-2427.

Trapani, J. A. 1995. Target cell apoptosis induced by cytotoxic T cells and natural killer cells involves synergy between the pore-forming protein, perforin, and the serine protease, granzyme B. Aust. N. Z. J. Med. 25:793-799. https://doi.org/10.1111/j.1445-5994.1995 .tb02883.x.

Wedlock, D. N., M. Denis, J. Lacy-Hulbert, and B. M. Buddle. 2008. Interleukin-1 $\beta$ infusion in bovine mammary glands prior to challenge with Streptococcus uberis reduces bacterial growth but causes sterile mastitis. Vet. Res. Commun. 32:439-447. https://doi.org/ 10.1007/s11259-008-9044-z.

Wheeler, B., and M. Torchiano. 2010. lmPerm: Permutation tests for linear models. $\mathrm{R}$ package version 1(1.2). Accessed June 15-21, 2018. https://CRAN.R-project.org/package $=$ lmPerm.

Wickham, H. 2016. ggplot2: Elegant graphics for data analysis. Springer, New York, NY.

Xue, H., D. Mainville, W. You, and R. M. Nayga. 2010. Consumer preferences and willingness to pay for grass-fed beef: Empirical evidence from in-store experiments. Food Qual. Prefer. 21:857-866. https://doi.org/10.1016/j.foodqual.2010.05.004.

Yu, P., D. A. Christensen, J. J. McKinnon, and J. D. Markert. 2003. Effect of variety and maturity stage on chemical composition, carbohydrate and protein subfractions, in vitro rumen degradability and energy values of timothy and alfalfa. Can. J. Anim. Sci. 83:279-290. https://doi.org/10.4141/A02-053. 